\title{
Oxidative esterification of acetol with methanol to methyl pyruvate over hydroxyapatite supported gold catalyst: Essential roles of acid-base properties
}

\author{
Yan Wan ${ }^{a}$, Congcong Zheng a, Xianchi Lei ${ }^{a}$, Mengqi Zhuanga ${ }^{a}$, Jinhan Lin a, Wenda Hu ${ }^{a}$, \\ Jingdong Lin ${ }^{\mathrm{a}, \mathrm{c}}$, Shaolong Wan ${ }^{\mathrm{a}, \mathrm{b}, \mathrm{c}, *}$, , Yong Wang ${ }^{\mathrm{d}}$ \\ a College of Chemistry and Chemical Engineering, Xiamen University, Xiamen 361005, Fujian, China \\ ${ }^{\mathrm{b}}$ Collaborative Innovation Center of Chemistry for Energy Materials, Xiamen University, Xiamen 361005, Fujian, China \\ c National Engineering Laboratory for Green Chemical Productions of Alcohols-Ethers-Esters, Xiamen University, Xiamen 361005, Fujian, China \\ ${ }^{\mathrm{d}}$ Voiland School of Chemical Engineering and Bioengineering, Washington State University, Pullman, Washington 99164, United States
}

\section{A R T I C L E I N F O}

\section{Article history:}

Received 27 March 2019

Accepted 29 March 2019

Published 5 November 2019

\section{Keywords:}

Acetol

Acid-base properties

Gold

Hydroxyapatite

Methyl pyruvate

\section{A B S T R A C T}

Acetol is a major light oxygenate and readily produced from staged or fast pyrolysis of lignocellulose biomass. Herein we report that acetol can be selectively converted to methyl pyruvate, an important fine chemical, through oxidative esterification over Au-based catalysts. Detailed experimental studies showed that $\mathrm{Au}$ on amphoteric supports with appropriate strength and balanced ratio of acid and base sites can facilitate the desired oxidative-esterification pathway without accelerating undesired aldol-condensation or Cannizzaro reactions. In particular, hydroxyapatite (with a $\mathrm{Ca} / \mathrm{P}$ ratio of 1.62) supported $\mathrm{Au}$ achieved $87 \%$ selectivity to methyl pyruvate at an acetol conversion of $62 \%$.

(C) 2019, Dalian Institute of Chemical Physics, Chinese Academy of Sciences. Published by Elsevier B.V. All rights reserved.

\section{Introduction}

For the past decade, lignocellulose biomass pyrolysis coupled with in-situ or ex-situ catalytic upgrading has been extensively used to produce transportation fuels or value-added chemicals directly from the abundant and renewable carbon resources [1-3]. However, the liquid pyrolysis oil consists of numerous different oxygenated molecules, thus exerting major obstacles for any feasible catalytic process design without severely sacrificing $\mathrm{C}$ and $\mathrm{H}$ efficiency [4]. An alternative approach is staged pyrolysis in which bio-oil is first fractionated into relatively simple cuts of concentrated products. Light compounds can then be selectively converted to value-added chemicals while the lignin-derived heavy compounds can be upgraded to transportation fuels [5]. This approach is expected to achieve improved atom efficiency and more importantly less challenge toward catalyst design. Along with this line, acetol is one of the major light pyrolysis products from staged pyrolysis of biomass that is conducted at relatively low temperature (473-573 K) [6]. Acetol is very active and usually regarded as a culprit of poor stability of bio-oil. It is highly desired to convert acetol to stable and value-added chemicals. Our recent work showed that with dealuminated Sn-beta supported gold catalyst under base-free conditions, acetol can be selectively con-

\footnotetext{
* Corresponding author. E-mail: swan@xmu.edu.cn

This work was supported by the National Natural Science Foundation of China (91545114, 91545203, and 21576227), and the 985 Program of the Chemistry and Chemical Engineering disciplines of Xiamen University.

DOI: S1872-2067(19)63368-1 | http://www.sciencedirect.com/science/journal/18722067 | Chin. J. Catal., Vol. 40, No. 11, November 2019
} 
verted to lactic acid [7] with a higher yield and improved catalyst stability compared to the earlier literature reports with inorganic base addition or base supported catalysts $[8,9]$. Herein we report that another important chemical, namely methyl pyruvate, can be synthesized from acetol via oxidative esterification over Au-based catalysts, further diversifying the applications of acetol derived from renewable biomass.

The methyl ester of pyruvic acid, namely methyl pyruvate, is one of the important chemical materials, and together with other pyruvates is widely used as intermediates for the synthesis of perfume, polymer industry, food additives, amino acids, agrochemicals, and drugs [10]. Currently methyl pyruvate is mainly produced by the esterification of pyruvic acid with methanol or the oxidation of methyl lactate [11]. Both processes are confronted with the use of enormous amounta of inorganic additives, increasing the production cost and environmental pressure related to waste disposal. Development of an alternative and environmentally friendly route from renewable resources is highly desired. This motivates us to explore an efficient one-pot synthesis of methyl pyruvate from acetol without using inorganic additives.

While conversion of primary alcohols to methyl esters has been well studied [12-15], direct oxidative esterification of acetol has not been systematically investigated under base-free conditions based on the best of our knowledge. The aerobic oxidation of alcohols over supported gold catalysts has attracted considerable interest because of the superior catalytic oxidation performance and improved resistance to oxygen poisoning compared to Pt-group metals [16]. Moreover, the presence of basic condition such as $\mathrm{NaOH}$ [17-21] or base support $[14,22-26]$ on $\mathrm{Au}$ catalysts is generally deemed necessary to accelerate the kinetic-relevant oxidation steps via $\beta-\mathrm{H}$ elimination, i.e. deprotonation of hydroxyl group in the alcohols or intermediates to form the aldehydes [27,28]. Indeed, catalysts with base supports such as $\mathrm{Au} / \mathrm{MgO}[25,29], \mathrm{Au} / \mathrm{Al}_{2} \mathrm{O}_{3}$ [22], $\mathrm{Au} / \mathrm{HT}$ [26], and $\mathrm{Au} / \mathrm{ZrO}_{2}$ [13,14] showed superior catalytic activity for the oxidation of alcohols in the absence of base additives. However, the presence of basicity on the support is not well correlated with the catalyst activity in the case of the alcohol oxidative esterification. Instead, the amphoteric catalysts containing both basicity and proper acidity such as $\mathrm{Au} / \mathrm{ZrO}_{2}$ [30], $\mathrm{Au} / \mathrm{ZnO}$ [31], $\mathrm{Au} / \beta-\mathrm{Ga}_{2} \mathrm{O}_{3}$ [32], and $\mathrm{Au} / \mathrm{Ga}_{3} \mathrm{Al}_{3} \mathrm{O}_{9}$ [33] are more efficient for the overall oxidative esterification compared to the catalysts containing only basicity. This appears to be reasonable, as the favorable pathway is generally believed to proceed via the oxidation of primary alcohol to aldehyde, followed by the reaction with alcohol to form hemiacetal intermediate, which is then further oxidized to the corresponding ester [34-36]. It has been reported that the condensation of methanol and aldehyde to form hemiacetal has a low energy barrier in the presence of acid sites [35,36]. In addition, gold nanoparticles can be better stabilized by the Lewis acid inherent on the supports [37]. On the other hand, aldehyde can be further converted into stable acetal in the presence of strong acid sites [38]. Therefore, appropriate acidity of the amphoteric supports would have beneficial effect on the catalytic selectivity of Au-based catalysts.
Considering the extremely active nature of acetol, as featured by the existence of neighboring carbonyl and hydroxyl groups, acetol may involve more complex reaction chemistry and thus present more challenges to catalyst design, as compared to primary alcohol discussed above. Here, we show that the combination of the support with fine-tuned acid-base properties and the Au-based oxidation catalyst can selectively convert acetol to methyl pyruvate in one pot. Au-based catalysts with different supports such as $\mathrm{SiO}_{2}, \mathrm{MgO}_{2} \mathrm{TiO}_{2}, \mathrm{Hy}-$ drotalcite (HT), $\gamma-\mathrm{Al}_{2} \mathrm{O}_{3}, \mathrm{ZrO}_{2}, \mathrm{ZnO}$, and HAP were investigated. Among all these catalysts, $\mathrm{Au} / \mathrm{HAP}$ with appropriate acid-base nature (a Ca to $P$ ratio of 1.62) exhibited the best catalytic performance. The possible reaction pathway toward the oxidative esterification was revealed to go through the formation of pyruvaldehyde intermediate and the subsequent hemiactal mechanism.

\section{Experimental}

\subsection{Chemicals and materials}

Acetol (95\% purity) and pyruvaldehyde (80\% purity) were obtained from Alfa Aesar. Methyl pyruvate (98\% purity) and methyl lactate (90\% purity) were obtained from J\&K Scientific Ltd. Ammonia solution (25\%), $\quad\left(\mathrm{NH}_{4}\right)_{2} \mathrm{HPO}_{4} \quad$ (99\%), $\mathrm{Ca}\left(\mathrm{NO}_{3}\right)_{2} \cdot 4 \mathrm{H}_{2} \mathrm{O}$ (99\%), and 1,4-dioxane were obtained from Aladdin. $\mathrm{HAuCl}_{4}$ (99.5\%), urea (99\%), methanol, $\mathrm{SiO}_{2}, \mathrm{MgO}$, $\mathrm{TiO}_{2}, \gamma-\mathrm{Al}_{2} \mathrm{O}_{3}, \mathrm{ZnO}$, and hydrotalcite were supplied by Sinopharm Chemical (Shanghai, China) and used without further purification.

\subsection{Catalyst synthesis}

The acid-base bifunctional hydroxyapatite was synthesized by a co-precipitation method [39]. Briefly, $3.96 \mathrm{~g}$ of $\left(\mathrm{NH}_{4}\right)_{2} \mathrm{HPO}_{4}$ and the desired amount of $\mathrm{Ca}\left(\mathrm{NO}_{3}\right)_{2} \cdot 4 \mathrm{H}_{2} \mathrm{O}$ were dissolved in $100 \mathrm{~mL}$ deionized water, respectively, both of which was adjusted to a $\mathrm{pH}$ of 10.0 with $25 \mathrm{wt} \%$ ammonia solution. Then the obtained $\left(\mathrm{NH}_{4}\right)_{2} \mathrm{HPO}_{4}$ solution was added dropwise to that of $\mathrm{Ca}\left(\mathrm{NO}_{3}\right)_{2} \cdot 4 \mathrm{H}_{2} \mathrm{O}$ under stirring, with the $\mathrm{pH}$ of the mixture solution maintained at 10.0. After aging for $24 \mathrm{~h}$, the milk white precipitate was washed with deionized water and calcined at $873 \mathrm{~K}$ for $2 \mathrm{~h}$ in a muffle furnace. A variety of HAPs were thus synthesized with initial ratios of $\mathrm{Ca}$ to $\mathrm{P}(1.50,1.67,1.80)$ by addition of different amounts of $\mathrm{Ca}\left(\mathrm{NO}_{3}\right)_{2} \cdot 4 \mathrm{H}_{2} \mathrm{O}$. The final samples with different $\mathrm{Ca} / \mathrm{P}$ molar ratios were denoted as HAP- $x(x$ $=\mathrm{Ca} / \mathrm{P}$ molar ratio).

The supported gold catalysts were prepared by using the deposition-precipitation (DP) method [40]. Typically, the support was added into the mix solution containing a certain amount of $\mathrm{HAuCl}_{4}$ and urea (urea/Au = 150, molar ratio). The suspension was vigorously stirred at $353 \mathrm{~K}$ for $4 \mathrm{~h}$, and after that the solid product was filtered and washed with deionized water to remove the chlorine. The resulting powder was dried at $353 \mathrm{~K}$ overnight and then calcined in air at $773 \mathrm{~K}$ for $2 \mathrm{~h}$. The final catalysts were stored in a desiccator shielded from light. 


\subsection{Catalyst characterization}

XRD patterns of the samples were collected on a Rigaku UItima IV X-ray diffractometer with a $\mathrm{Cu} K_{\alpha} \mathrm{X}$-ray source $(35 \mathrm{kV}$ and $15 \mathrm{~mA}$ ) from $20^{\circ}$ to $70^{\circ}$ at a scan speed of $2 \theta=10^{\circ} / \mathrm{min}$. Fourier transform infrared (FT-IR) spectra were measured on a Nicolet 6700 instrument equipped with an MCT detector at a spectral resolution of $4 \mathrm{~cm}^{-1}$ using $\mathrm{KBr}$ pellets.

Transmission electron microscopy measurements were performed on a JEM-2100 electron microscope at an acceleration voltage of $200 \mathrm{kV}$. The mean diameter of gold nanoparticles in the samples was measured and the particle diameter distribution was statistically analyzed.

The Ca/P molar ratio and the gold content of the samples were determined by inductively coupled plasma-optical emission spectrometry (ICP-OES), using a Thermo IRIS Intrepid II XSP atomic emission spectrometer. BET surface areas for the samples were obtained by $\mathrm{N}_{2}$ physical adsorption at $77 \mathrm{~K}$ using a Micromeritics TriStar II 3020 porosimetry analyzer.

The strength of acidity $\left(\mathrm{H}_{0}\right)$ and basicity $(\mathrm{H}$-) for each catalyst support was analyzed qualitatively by Hammett titration. The following Hammett indicators were used: methyl yellow $\left(\mathrm{p} K_{\mathrm{a}}=3.3\right)$, methyl red $\left(\mathrm{p} K_{\mathrm{a}}=4.8\right)$, neutral red $\left(\mathrm{p} K_{\mathrm{a}}=6.8\right)$, bromothymol blue $\left(\mathrm{p} K_{\mathrm{a}}=7.2\right)$, phenolphthalein $\left(\mathrm{p} K_{\mathrm{a}}=9.8\right)$, alizarin yellow $\mathrm{R}\left(\mathrm{p} K_{\mathrm{a}}=11.0\right)$, indigo carmine $\left(\mathrm{p} K_{\mathrm{a}}=12.2\right)$, 2,4-diniitroaniline $\left(\mathrm{p} K_{\mathrm{a}}=15\right)$, 4-nitroaniline $\left(\mathrm{p} K_{\mathrm{a}}=18.4\right)$, and 4-chloroaniline $\left(\mathrm{p} K_{\mathrm{a}}=26.5\right)$. Typically, $100 \mathrm{mg}$ of the dried sample was covered by petroleum ether and then a solution of dissolved indicators was added. After vigorous shaking, the colour variation of each catalyst support was distinguished [41].

Ammonia temperature-programmed desorption ( $\mathrm{NH}_{3}$-TPD) and carbon dioxide temperature-programmed desorption ( $\mathrm{CO}_{2}$-TPD) measurements were performed on a Micromeritics ASAP 2920 apparatus. Typically, the sample was loaded and preheated in a quartz reactor with high purity He (99.99\%) flow at $383 \mathrm{~K}$ for $2 \mathrm{~h}$, followed by cooling down to $373 \mathrm{~K}$. The adsorption of $\mathrm{NH}_{3}$ or $\mathrm{CO}_{2}$ was performed at $373 \mathrm{~K}$ in an $\mathrm{NH}_{3}-\mathrm{He}$ mixture $\left(10\right.$ vol $\% \mathrm{NH}_{3}$ ) or a $\mathrm{CO}_{2}$-He mixture $\left(10 \mathrm{vol} \% \mathrm{CO}_{2}\right)$ for $1 \mathrm{~h}$. Then the temperature was raised to $973 \mathrm{~K}$ at a rate of 10 $\mathrm{K} /$ min. The desorbed $\mathrm{NH}_{3}$ or $\mathrm{CO}_{2}$ was detected with a mass spectrometer (ThermoStar GSD $301 \mathrm{~T} 2$ ) by monitoring the signal with $m / e=17$ or $m / e=44$.

\subsection{Catalytic evaluation}

The oxidative esterification of acetol was performed using a batch-type Teflon-lined stainless-steel autoclave. For each experiment, catalyst $(300 \mathrm{mg})$, methanol $(20 \mathrm{~mL})$, and acetol $(2$ mmol) were added into the autoclave. The reactor was purged with pure $\mathrm{O}_{2}$ several times to remove the residual air, and then pressurized to a certain pressure. The sealed system was heated up to the set temperature and the reaction was kept under vigilant stirring for a given time. After that, the reactor was cooled to room temperature in cold water, followed by the release of reactant gas and separation of the catalyst from the products with filtration.
The products were identified by GC-MS (Agilent Technologies, 7890B GC system and 5977B MSD) equipped with a VF-1701 ms capillary column $(60 \mathrm{~m} \times 0.25 \mathrm{~mm} \times 0.25 \mu \mathrm{m})$. The verified products were further quantitative analyzed by a gas chromatograph (model GC 2060 by Shanghai Ruimin Instruments, Inc.) equipped with a DB-WAXETR capillary column (50 $\mathrm{m} \times 0.32 \mathrm{~mm} \times 1.0 \mu \mathrm{m}$ ) and a flame ionization detector (FID), where 1,4-dioxane was always added as an external standard.

The recycling tests were carried out with the same reactor under optimal reaction conditions. Prior to each recycle test, the catalyst was washed with deionized water and dried at 353 K overnight.

\section{Results and discussion}

\subsection{Catalyst characterization}

The acid/base nature of each catalyst support was estimated quantitatively using Hammett indicator. As displayed in

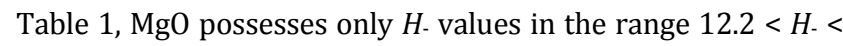
15 , which represent the strongest alkalinity. In contrast, $\mathrm{SiO}_{2}$ and $\mathrm{TiO}_{2}$ do not seem to have any base sites but exhibit similar acid strength. The others have amphoteric properties, where both acid and base sites are present in the hydrotalcite, $\gamma-\mathrm{Al}_{2} \mathrm{O}_{3}$, $\mathrm{ZnO}$, and HAP. Hydrotalcite (HT) possesses stronger base sites in the range $11.0<H-<12.2$, followed by $\gamma-\mathrm{Al}_{2} \mathrm{O}_{3}$ and $\mathrm{ZnO}(9.8<$ $H_{-}<11.0$ ), with HAP being the weakest (about $7.2<H_{-}<9.8$ ). However, HAP exhibits the strongest acid sites of $3.3<H_{0}<4.8$ among all these amphoteric supports, and the measured acid strength follows the order $\mathrm{HAP}>\mathrm{HT}, \gamma-\mathrm{Al}_{2} \mathrm{O}_{3}>\mathrm{ZnO}$. Apparently, HAP prepared in our study is featured by the relatively strong acid strength but the weak base, which would play a key role toward the selective oxidative esterification of acetol as discussed later.

The physicochemical properties of prepared HAP and $\mathrm{Au} / \mathrm{HAP}$ catalysts are listed in Table 2 . The initial molar ratios of $\mathrm{Ca}$ to $\mathrm{P}$ in the preparation of HAP were 1.50, 1.67, and 1.80 for $\mathrm{Au} / \mathrm{HAP}-1.59, \mathrm{Au} / \mathrm{HAP}-1.62$, and $\mathrm{Au} / \mathrm{HAP}-1.65$ catalysts, respectively. ICP-OES analysis confirmed that the molar ratio of $\mathrm{Ca}$ to $\mathrm{P}$ of HAP increased with the increasing initial molar ratio of Ca to P. It should be noted that such ratios in the synthesized HAP samples slightly deviated from the initial input, reflecting the complexity of crystallization during the synthesis. After depositing Au nanoparticles, the molar ratio of Ca to P further changed slightly, probably due to the use of the urea during the

Table 1

Acid and base properties of various supports.

\begin{tabular}{lccc}
\hline Entry & Support & Acid strength & Base strength \\
\hline 1 & $\mathrm{SiO}_{2}$ & $3.3<H_{0}<4.8$ & - \\
2 & $\mathrm{MgO}$ & - & $12.2<H_{-}<15$ \\
3 & $\mathrm{Hydrotalcite}$ & $4.8<H_{0}<6.8$ & $11.0<H_{-}<12.2$ \\
4 & $\mathrm{TiO}_{2}$ & $3.3<H_{0}<4.8$ & - \\
5 & $\gamma-\mathrm{Al}_{2} \mathrm{O}_{3}$ & $4.8<H_{0}<6.8$ & $9.8<H_{-}<11.0$ \\
6 & $\mathrm{ZnO}$ & $6.8<H_{0}<7.2$ & $9.8<H_{-}<11.0$ \\
7 & $\mathrm{HAP}^{\text {a }}$ & $3.3<H_{0}<4.8$ & $7.2<H_{-}<9.8$ \\
\hline
\end{tabular}

a HAP includes all the HAPs prepared in this work with the ratio of Ca to P varied from 1.59 to 1.65 . 
Table 2

Physicochemical properties for various Au/HAP catalysts.

\begin{tabular}{lcccccc}
\hline Catalyst & $\begin{array}{c}\text { Initial } \\
\mathrm{Ca} / \mathrm{P}\end{array}$ & $\begin{array}{c}\mathrm{Ca} / \mathrm{P} \text { of } \\
\mathrm{HAP}^{\mathrm{a}}\end{array}$ & $\begin{array}{c}\mathrm{Ca} / \mathrm{P} \text { of } \\
\mathrm{Au} / \mathrm{HAP}\end{array}$ & $\begin{array}{c}\mathrm{Au} \\
(\mathrm{wt} \%)\end{array}$ & $\begin{array}{c}d_{\mathrm{Au}}{ }^{\mathrm{b}} \\
(\mathrm{nm})\end{array}$ & $\begin{array}{c}S_{\mathrm{BET}}{ }^{\mathrm{c}} \\
\left(\mathrm{m}^{2} / \mathrm{g}\right)\end{array}$ \\
\hline $\mathrm{Au} / \mathrm{HAP}-1.59$ & 1.50 & 1.53 & 1.59 & 0.99 & 3.4 & 68 \\
$\mathrm{Au} / \mathrm{HAP}-1.62$ & 1.67 & 1.60 & 1.62 & 0.97 & 3.6 & 56 \\
$\mathrm{Au} / \mathrm{HAP}-1.65$ & 1.80 & 1.66 & 1.65 & 0.98 & 3.6 & 54
\end{tabular}

a Obtained from ICP-OES. b Evaluated from TEM. c Calculated from $\mathrm{N}_{2}$ physisorption.

preparation of supported Au catalysts. As summarized in Table 2, the measured Au content was approximately $0.98 \mathrm{wt} \%$, close to the nominal loading for all samples. The Au particles were homogeneously distributed with uniform particle sizes, as shown in Fig. 1. The mean particle sizes of Au are about 3.4-3.6 $\mathrm{nm}$, similar for all these catalysts.

It is known that HAP is an amphoteric phosphate having a flexible structure, where the acid/base properties can be regulated by adjusting the molar ratio of Ca to $\mathrm{P}$ of samples. HAPs possess acidity due to the deficiency of $\mathrm{Ca}^{2+}$ and basicity resulting from the excess of $\mathrm{Ca}^{2+}$ [42]. These nonstoichiometric HAPs may be charge balanced by cationic (e.g., $\mathrm{H}^{+}$) and or anionic ions (e.g., $\mathrm{CO}_{3}{ }^{2-}$ ) [43]. Therefore, for the HAP and supported HAP samples, the higher the ratio of Ca to $\mathrm{P}$ gets, the lower density of acid sites and the higher number of base sites. The relative ratio of acid-base sites could play a key factor on the product selectivity in the oxidative esterification of acetol. Thus the synthesized HAPs with different ratios of Ca to $\mathrm{P}$ above were carefully characterized.

Fig. 2 shows FTIR spectra of the prepared HAP materials, which are in good agreement with those of hydroxyapatite previously reported [44]. All samples display absorption peaks at $576,603,962,1043$, and $1096 \mathrm{~cm}^{-1}$, which can be assigned to $\mathrm{PO}_{4}{ }^{3-}$ ions [45]. The bands at 3572 and $632 \mathrm{~cm}^{-1}$ are due to the stretching vibration modes of hydroxyl groups in the HAP crystal, while broad bands at 3427 and $1637 \mathrm{~cm}^{-1}$ are probably attributed to adsorbed water [46]. The characteristic band at $1385 \mathrm{~cm}^{-1}$ arises from nitrite species resulting from the residual precursors [39]. Besides, the weak bands at 1412 and 1455 $\mathrm{cm}^{-1}$ may correspond to traces of $\mathrm{CO}_{3}{ }^{2-}$ impurity ions, which might replace $\mathrm{PO}_{4}{ }^{3-}$ ions in hydroxyapatite lattice [47]. The

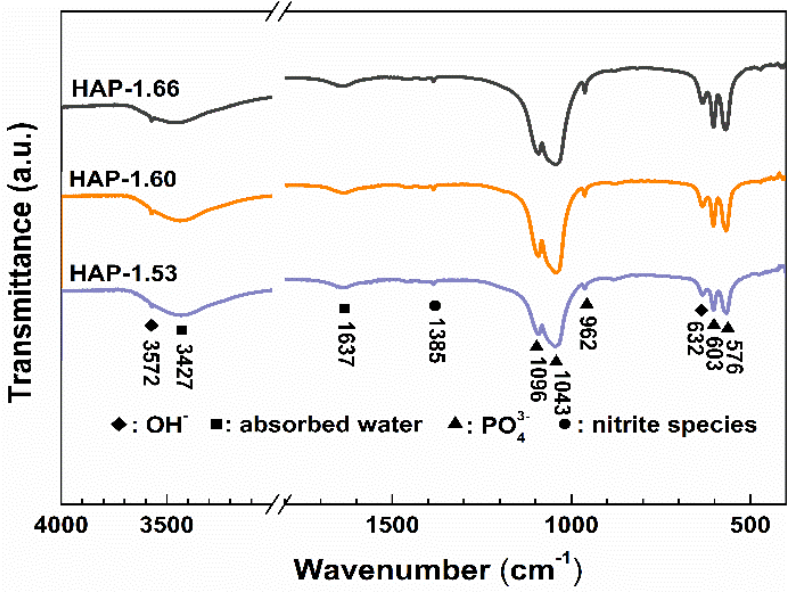

Fig. 2. Infrared spectra for synthesized HAP with different ratios of $\mathrm{Ca} / \mathrm{P}$.
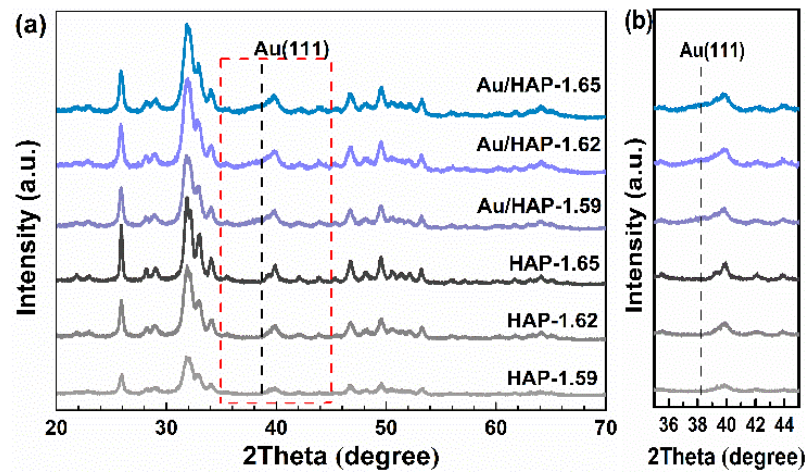

Fig. 3. (a) XRD patterns of HAP and Au/HAP; (b) Blow out of the box in (a).

powder XRD patterns of HAP and Au/HAP, shown in Fig. 3, are consistent with the featured characteristic reflections of pure hydroxyapatite (JCPDS 09-0432). No diffraction peak for $\mathrm{CaO}$ or $\mathrm{Ca}_{3}\left(\mathrm{PO}_{4}\right)_{2}$ was observed in the all XRD patterns. These XRD results confirm that the crystal lattice structure of hydroxyapatite was well maintained after the loading of Au nanoparticles. Diffuse diffraction peak of $\mathrm{Au}(111)$ at $2 \theta=38.2^{\circ}$ can be also observed for $\mathrm{Au} / \mathrm{HAP}$ samples, indicating the presence of the Au nanoparticles with a size consistent with the TEM results.

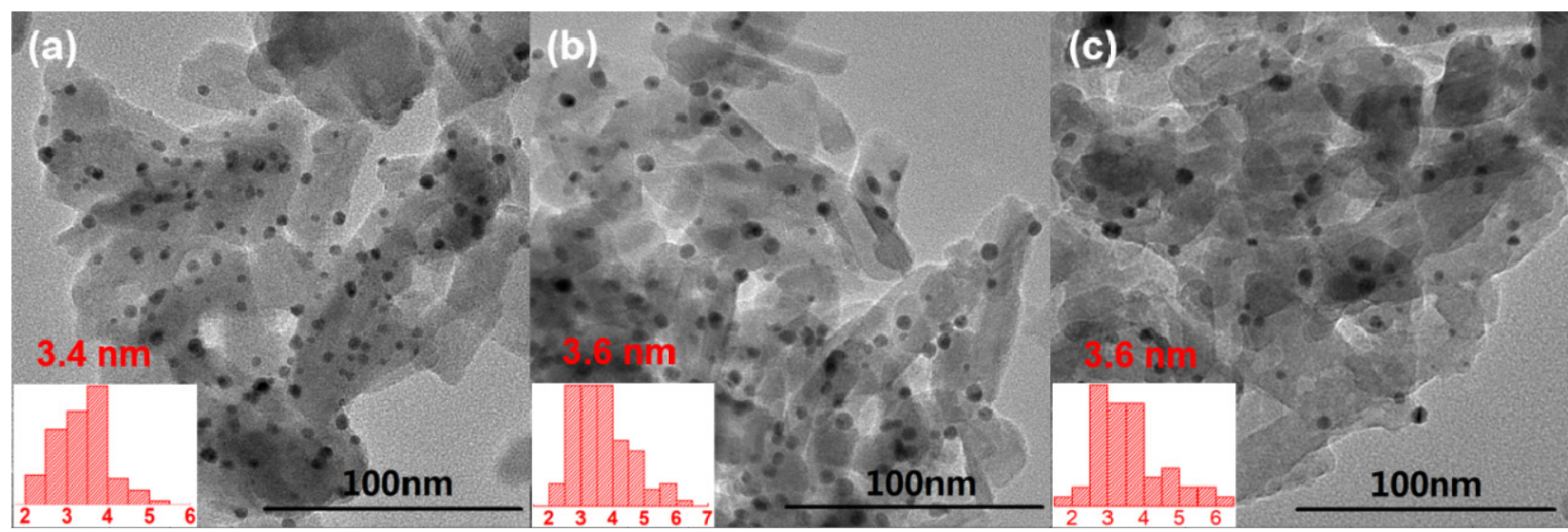

Fig. 1. TEM images of (a) Au/HAP-1.59, (b) Au/HAP-1.62, and (c) Au/HAP-1.65 and particle size distribution of Au nanoparticles. 

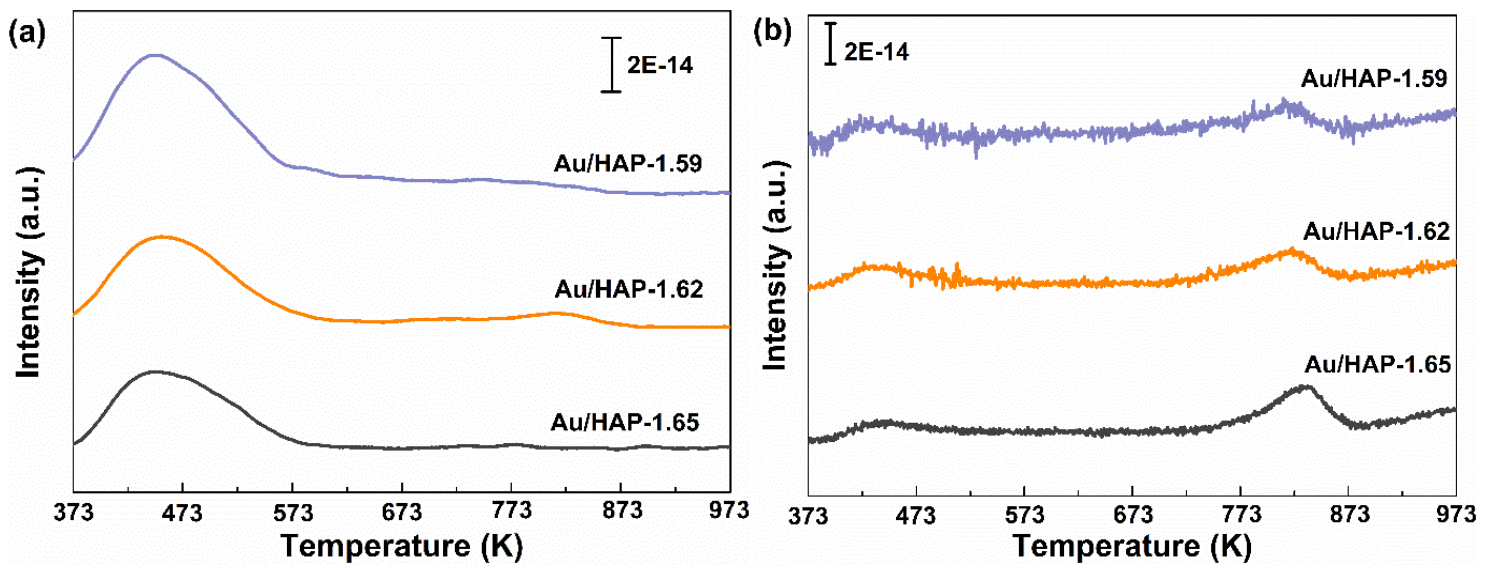

Fig. 4. (a) $\mathrm{NH}_{3}$-TPD and (b) $\mathrm{CO}_{2}$-TPD profiles of $\mathrm{Au} / \mathrm{HAP}$ with $\mathrm{Ca} / \mathrm{P}=1.59,1.62$, and 1.65 .

As showed in Fig. 4, $\mathrm{NH}_{3}$-TPD and $\mathrm{CO}_{2}$-TPD were carried out to investigate the acid/base properties of synthesized Au/HAP catalysts. $\mathrm{Au} / \mathrm{HAPs}$ with different $\mathrm{Ca} / \mathrm{P}$ exhibited qualitatively similar $\mathrm{NH}_{3}$-TPD profiles, featuring only one obvious peak at about 449 K. Similar $\mathrm{CO}_{2}$-TPD patterns were also observed, where the position of the first $\mathrm{CO}_{2}$ peak around $443 \mathrm{~K}$ shifted toward slightly higher temperatures as the $\mathrm{Ca} / \mathrm{P}$ of samples increased. The second signal detected at about $823 \mathrm{~K}$ was probably due to the decomposition of HAP structure, as suggested by Xu et. al. [43]. The quantitative densities of acid/base sites based on those TPD results are summarized in Table 3 . Apparently, the density of acid sites decreased with the increase in the $\mathrm{Ca} / \mathrm{P}$ ratio from 1.59 to 1.65 , while a reverse trend was found in the density of base sites, which is consistent with previous work [43].

\subsection{Catalytic behavior of Au nanoparticles loaded on supports with varied acid/base nature}

Oxidative esterification of acetol was evaluated on catalysts prepared on various supports with the same gold loading. Striking difference was observed due to the distinct acid/base properties, as listed in Table 4. It can be seen that catalysts prepared on supports with only acid properties such as $\mathrm{Au} / \mathrm{SiO}_{2}$ and $\mathrm{Au} / \mathrm{TiO}_{2}$ exhibit very poor methyl pyruvate (MPA) selectivity, i.e., $0 \%$ and $8 \%$ on $\mathrm{Au} / \mathrm{SiO}_{2}$ and $\mathrm{Au} / \mathrm{TiO}_{2}$, respectively. Extra base addition like $\mathrm{NaOCH}_{3}$ upon $\mathrm{Au} / \mathrm{TiO}_{2}$ could enhance the reaction rate of acetol, but result in mainly methyl lactate (MLA) probably due to the base-catalyzed Cannizzaro reaction [15]. Poor selectivity to MPA was also observed on catalysts prepared on supports with only base properties such as $\mathrm{Au} / \mathrm{MgO}$, which showed only $2 \% \mathrm{MPA}$ at $54 \%$ conversion.

Table 3

Surface acid/base properties of the Au/HAP.

\begin{tabular}{lcc}
\hline Catalyst & $\begin{array}{c}\text { Acid site density } \\
(\mu \mathrm{mol} / \mathrm{g})\end{array}$ & $\begin{array}{c}\text { Base site density } \\
(\mu \mathrm{mol} / \mathrm{g})\end{array}$ \\
\hline $\mathrm{Au} / \mathrm{HAP}-1.59$ & 3.34 & 2.87 \\
$\mathrm{Au} / \mathrm{HAP}-1.62$ & 2.72 & 3.40 \\
$\mathrm{Au} / \mathrm{HAP}-1.65$ & 2.21 & 4.00 \\
\hline
\end{tabular}

This suggests that the catalyst supports containing mono-functional acid or base sites do not favor the formation of MPA. It should be noted that the side reactions such as aldol-condensation of acetol would readily proceed on acid or base sites, resulting in the formation of heavy compounds undetected by GC, and consequently poor mass balance in Table 4 . Interestingly, $\mathrm{Au}$ on amphoteric supports containing both acid sites and base sites such as $\mathrm{Au} / \gamma-\mathrm{Al}_{2} \mathrm{O}_{3}, \mathrm{Au} / \mathrm{ZnO}$, and $\mathrm{Au} / \mathrm{HAP}$ all resulted in much improved performance. Both $\gamma-\mathrm{Al}_{2} \mathrm{O}_{3}$ and $\mathrm{ZnO}$ possess comparable base strength (Table 1), and catalysts based on these two supports exhibited a much-improved selectivity toward MPA (50\%). However, relatively weaker acid sites on $\mathrm{ZnO}$ support appeared to promote the formation of methyl lactate (MLA), with $30 \%$ selectivity at 38\% conversion, which is much higher than that $(14 \%)$ from $\gamma-\mathrm{Al}_{2} \mathrm{O}_{3}$ support. Strikingly, $\mathrm{Au} / \mathrm{HAP}-1.65$, which contains the strongest acid and but weakest base sites among these three amphoteric supports, exhibited the best catalytic performance (MPA selectivity up to $77 \%$ at $62 \%$ conversion, shown in entry 7 of Table 4 ). The selectivities toward side products include MLA and MAA (methyl acetate) were all kept below 5\%. A slightly high selectivity to MDP (methyl 2,2-dimethoxypropionate) (6\%) is not an iss it worthwhile ue since it can be eventually converted to MPA in a longer reaction time as discussed below. The only exception for the amphoteric supports lies in Au/HT, which achieves only 8\% MPA

Table 4

The effect of supports on the oxidative esterification of acetol with methanol.

\begin{tabular}{lcccccc}
\hline \multirow{2}{*}{ Entry } & \multirow{2}{*}{ Catalyst } & Conversion & \multicolumn{4}{c}{ Selectivity (\%) } \\
\cline { 4 - 7 } & & $(\%)$ & MPA & MLA & MAA & MDP \\
\hline 1 & $\mathrm{Au} / \mathrm{SiO}_{2}$ & 21 & 0 & 1 & 2 & 0 \\
2 & $\mathrm{Au} / \mathrm{MgO}$ & 54 & 2 & 4 & 2 & 0 \\
3 & $\mathrm{Au} / \mathrm{TiO}_{2}$ & 64 & 8 & 10 & 4 & 2 \\
4 & $\mathrm{Au} / \mathrm{HT}$ & 55 & 8 & 12 & 5 & 2 \\
5 & $\mathrm{Au} / \gamma-\mathrm{Al}_{2} \mathrm{O}_{3}$ & 75 & 48 & 14 & 5 & 0 \\
6 & $\mathrm{Au} / \mathrm{ZnO}$ & 38 & 53 & 30 & 3 & 2 \\
7 & $\mathrm{Au} / \mathrm{HAP}$ & 62 & 77 & 4 & 2 & 6 \\
\hline
\end{tabular}

Reaction conditions: acetol, $2 \mathrm{mmol}$; catalyst, $0.3 \mathrm{~g} ; \mathrm{O}_{2}, 1 \mathrm{MPa} ; \mathrm{CH}_{3} \mathrm{OH}$, $20 \mathrm{~mL} ; 373 \mathrm{~K}, 4 \mathrm{~h}$. Abbreviation: MPA, methyl pyruvate; MLA, methyl lactate; MAA, methyl acetate; MDP, methyl 2,2-dimethoxypropionate. 
Table 5

Catalytic performance of $\mathrm{Au} / \mathrm{HAP}$ with different ratios of $\mathrm{Ca}$ to $\mathrm{P}$ for the oxidative esterification of acetol with $\mathrm{CH}_{3} \mathrm{OH}$.

\begin{tabular}{lcccccc}
\hline \multirow{2}{*}{ Entry } & \multirow{2}{*}{ Catalyst } & Conversion & \multicolumn{4}{c}{ Selectivity (\%) } \\
\cline { 4 - 7 } & & $(\%)$ & MPA & MLA & MAA & MDP \\
\hline 1 & Au/HAP-1.59 & 63 & 75 & 5 & 2 & 10 \\
2 & $\mathrm{Au} / \mathrm{HAP}-1.62$ & 62 & 87 & 3 & 2 & 8 \\
3 & $\mathrm{Au} / \mathrm{HAP}-1.65$ & 62 & 77 & 4 & 2 & 6 \\
\hline
\end{tabular}

Reaction conditions: acetol, $2 \mathrm{mmol}$; catalyst, $0.3 \mathrm{~g} ; \mathrm{O}_{2}, 1 \mathrm{MPa} ; \mathrm{CH}_{3} \mathrm{OH}$ $20 \mathrm{~mL} ; 373 \mathrm{~K}, 4 \mathrm{~h}$.

selectivity, probably due to its strong base sites that enhance severely aldol-condensation mentioned above. All the above results demonstrate that the acid and base properties in the supports indeed play a key role on the selective conversion of acetol to methyl pyruvate. Therefore, it is worthwhile to fine-tune the acid and base properties in HAP, and further explore the synergistic effect to achieve the optimized product distribution.

\subsection{Activity measurements on $\mathrm{Au} / \mathrm{HAP}$}

In order to further understand the roles of acid-base properties on oxidative acetol esterification, Au/HAP catalysts with three different ratios of Ca to $\mathrm{P}$ were investigated. As seen in Table 5, all three catalysts showed a similar conversion, namely about $62 \%$ in 4 h's reaction, indicating a similar reactivity. However, the selectivity toward MPA did show a notable difference as affected by the ratio of Ca to P. Au/HAP-1.59 and $\mathrm{Au} / \mathrm{HAP}-1.65$ exhibited a comparable selectivity of $76 \%$, while $\mathrm{Au} / \mathrm{HAP}-1.62$ showed the best performance with $87 \%$ selectivity toward methyl pyruvate. The side products include MLA and MAA, which are all maintained at a low level, $<5 \%$ to MLA and $2 \%$ to MAA in all 3 cases. It should be noted that the selectivity toward MDP increased from $6 \%$ to $10 \%$, as the ratio of $\mathrm{Ca}$ to $\mathrm{P}$ decreased from 1.65 to 1.59 , corresponding to the monotonically increased acid sites in the catalysts.

The effect of temperature on the oxidative esterification of acetol was further studied using the optimized Au/HAP cata-

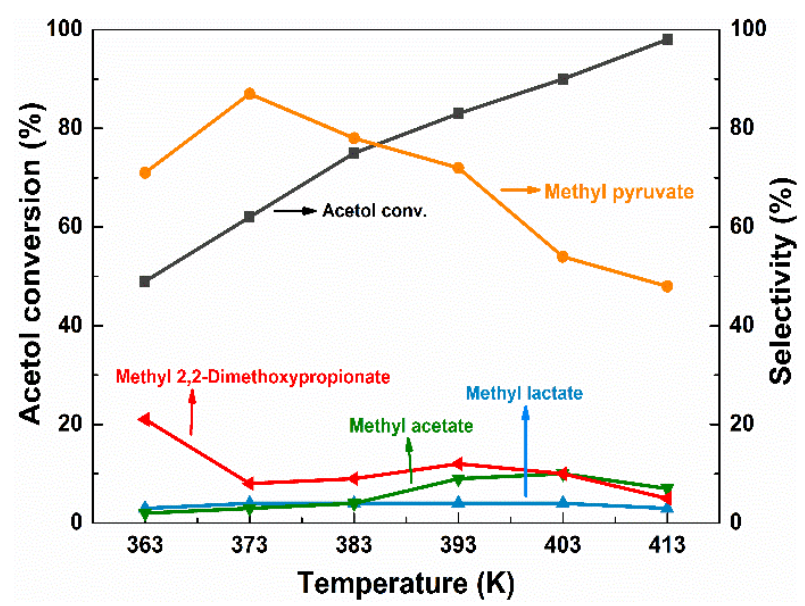

Fig. 5. Effect of reaction temperature on the conversion of acetol and selectivities of various products. Reaction conditions: acetol, $2 \mathrm{mmol}$; $0.97 \mathrm{wt} \% \mathrm{Au} / \mathrm{HAP}-1.62$ catalyst, $0.3 \mathrm{~g} ; \mathrm{O}_{2}, 1 \mathrm{MPa} ; \mathrm{CH}_{3} \mathrm{OH}, 20 \mathrm{~mL} ; 4 \mathrm{~h}$.

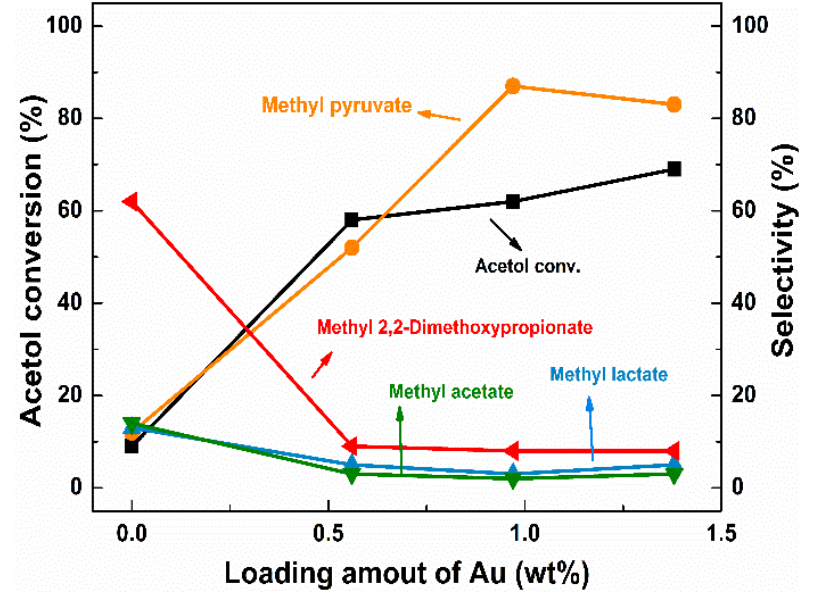

Fig. 6. Effect of loading amount of Au on the conversion of acetol and selectivities of various products. Reaction conditions: acetol, $2 \mathrm{mmol}$; $\mathrm{Au} / \mathrm{HAP}-1.62$ catalyst, $0.3 \mathrm{~g}$; $\mathrm{O}_{2}, 1 \mathrm{MPa}$; $\mathrm{CH}_{3} \mathrm{OH}, 20 \mathrm{~mL} ; 373 \mathrm{~K}, 4 \mathrm{~h}$.

lysts. As shown in Fig. 5, acetol conversion increases with reaction temperature from $363 \mathrm{~K}$ to $413 \mathrm{~K}$, while the selectivity of MPA reaches a maximum of $87 \%$ at $373 \mathrm{~K}$. Higher temperature would cause notable increase of methyl acetate, probably due to the enhanced decomposition. The temperature of $373 \mathrm{~K}$ is thus chosen for further studies discussed below.

The gold loadings were also studied, as shown in Fig. 6. With the bare HAP, the conversion is quite low, reaching $9 \%$ in $4 \mathrm{~h}$ with dominant formation of MDP. However, loading of 0.56 wt $\%$ gold nanoparticles strikingly accelerated the conversion of acetol to 58\%, and promoted the formation of MPA as a main product with $52 \%$ selectivity. The selectivity of MPA was further improved to $87 \%$ at a gold loading of $0.97 \mathrm{wt} \%$, whereas further increasing gold loading did not show appreciable benefit in both the reactivity and selectivity.

To study the stability of the optimized 0.97 wt $\%$ $\mathrm{Au} / \mathrm{HAP}-1.62$ catalyst, the spent catalyst after each run in oxidative esterification of acetol was collected and reused after filtration and washing with deionized water, and drying at 353 $\mathrm{K}$. The recovered $\mathrm{Au} / \mathrm{HAP}$ exhibited similar catalytic activity

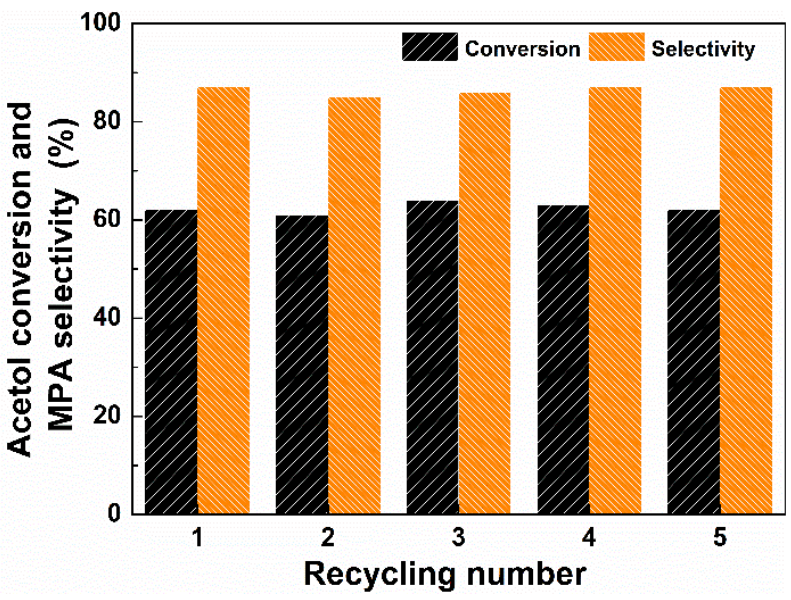

Fig. 7. Activity of Au/HAP-1.62 catalyst for oxidative esterification of acetol as a function of recycling number. Reaction conditions: acetol, 2 mmol; 0.97 wt $\% \mathrm{Au} / \mathrm{HAP}-1.62$ catalyst, $0.3 \mathrm{~g} ; \mathrm{O}_{2}, 1 \mathrm{MPa}$; $\mathrm{CH}_{3} \mathrm{OH}, 20 \mathrm{~mL}$; $373 \mathrm{~K}, 4 \mathrm{~h}$. 


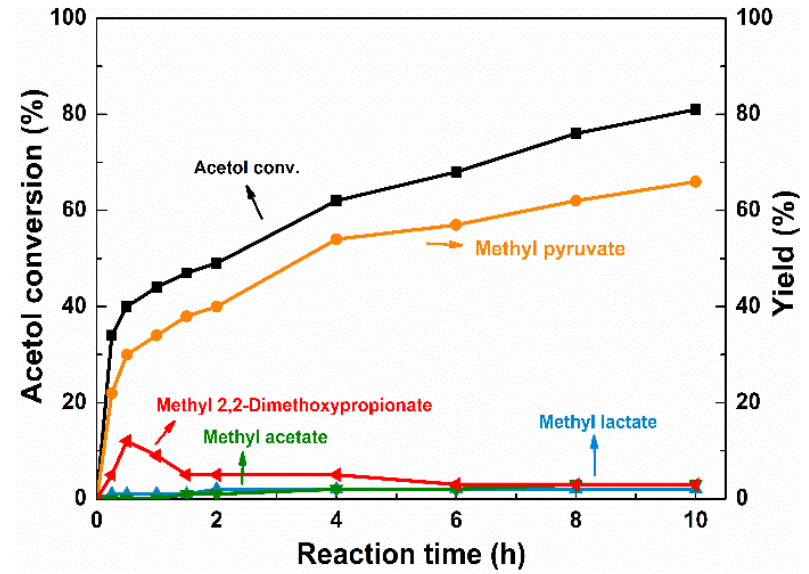

Fig. 8. Time course for the conversion of acetol and yield of various products. Reaction conditions: acetol, 2 mmol; $0.97 \mathrm{wt} \% \mathrm{Au} / \mathrm{HAP}-1.62$ catalyst, $0.3 \mathrm{~g} ; \mathrm{O}_{2}, 1 \mathrm{MPa} ; \mathrm{CH}_{3} \mathrm{OH}, 20 \mathrm{~mL} ; 373 \mathrm{~K}$.

(acetol conversion and selectivity toward MPA) for 5 cycles (Fig. 7), demonstrating excellent catalyst durability.

\subsection{Reaction pathways}

The time evolution of products was fully investigated to explore the possible reaction pathway, as presented in Fig. 8. The yield of methyl pyruvate increased along with the conversion of acetol, while methyl lactate and methyl acetate were both detected at the trace level over the entire course of reaction. It should be noted that the yield of methyl 2,2-dimethoxypropionate (MDP) increased up to a maximum of $12 \%$ at $30 \mathrm{~min}$ of reaction time, then dropped rapidly in $2 \mathrm{~h}$, followed by a gradual decrease until near disappearance. This suggests that MDP, as a ketal intermediate of MPA, would undergo subsequent reverse reaction, probably driven by more water produced as the oxidative esterification proceeds.

The pathway of oxidative esterification of acetol can be envisaged to proceed through PA as the intermediate, which then undergoes several possible routes toward methyl pyruvate, as depicted in Scheme 1. However, PA was not observed in our case, presumably because of its rapid consumption to the secondary products once formed. To elucidate the subsequent reaction network toward methyl pyruvate, tests using the pos-

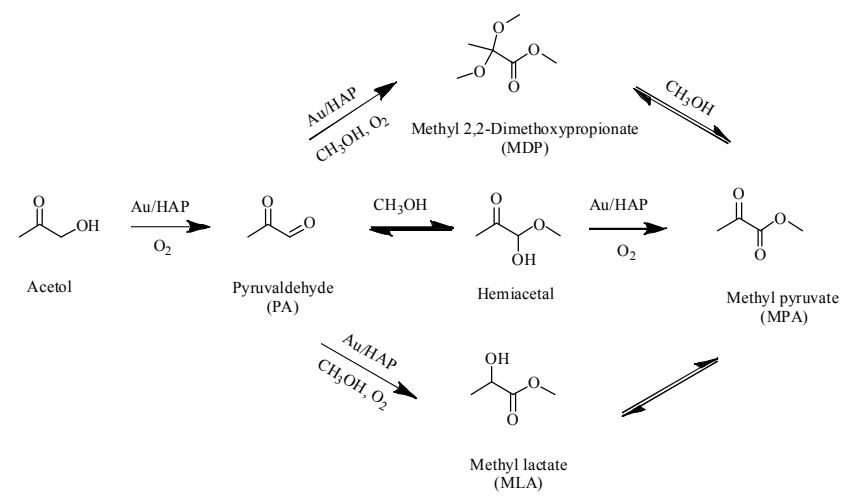

Scheme 1. Proposed reaction pathways for the oxidative esterification of acetol to methyl pyruvate over the Au/HAP-1.62.
Table 6

Catalytic performance of $\mathrm{Au} / \mathrm{HAP}$ for the oxidative esterification of different substrates with $\mathrm{CH}_{3} \mathrm{OH}$.

\begin{tabular}{lcccccc}
\hline \multirow{2}{*}{ Entry } & \multirow{2}{*}{ Substrate } & Conversion & \multicolumn{4}{c}{ Yield (\%) } \\
& $(\%)$ & MPA & MLA & MAA & MDP \\
\hline 1 & PA & $>99$ & 68 & 3 & 5 & 2 \\
2 & MPA & 5 & - & 1 & - & 3 \\
3 & MLA & 3 & - & 3 & - & - \\
4 & MDP a & 16 & 11 & - & - & - \\
\hline
\end{tabular}

Reaction conditions: substrate, $2 \mathrm{mmol}$; Au/HAP-1.62 catalyst, $0.3 \mathrm{~g} ; \mathrm{O}_{2}$, $1 \mathrm{MPa} ; \mathrm{CH}_{3} \mathrm{OH}, 20 \mathrm{~mL} ; 373 \mathrm{~K}, 4 \mathrm{~h}$; ${ }^{\text {SSolvent: }} 15 \mathrm{~mL}$ of $\mathrm{CH}_{3} \mathrm{OH}+5 \mathrm{~mL}$ of $\mathrm{H}_{2} \mathrm{O}$.

sible intermediates as the substrate other than acetol were performed. Indeed, the results started from PA, entry 1 in Table 6 , achieved the similar product distribution as those from acetol, which is consistent with the postulated reaction scenario in Scheme 1 (ca. through PA as the first step). With MLA as the reactants, only small extent of conversion to MPA is achieved, excluding its possibility as the major pathway. Similar conclusion can be applied to MDP, which under the same condition (15 mL of $\mathrm{CH}_{3} \mathrm{OH}+5 \mathrm{~mL}$ of $\mathrm{H}_{2} \mathrm{O}$ ) can only reach $11 \%$ yield of MPA with $16 \%$ conversion. It is generally believed that the route through carboxylic acid intermediate followed by subsequent esterification to the final ester product (i.e. MPA here) is unlikely to play a major role under the alcohol solvent $[29,48]$, which (namely pyruvic acid in this work) is indeed not observed in our case. Instead, the most likely pathway would probably proceed via first the formation of hemiacetal, and the subsequent oxidation to MPA, which is consistent with that proposed by the experimental and theoretical works based on the oxidative esterification of primary alcohols $[29,34-36,48]$. Both of these two steps would take place rather rapidly, thus leaving the intermediates present with amounts below the detection limit during the entire reaction, which is also in agreement with the other's work involving PA and hemiacetal as the intermediates $[29,48]$.

The results above clearly suggest that both the strength and the ratio of co-existed acid and basic sites play the key roles in affecting the PA selectivity, which must be closely correlated with the featured structure and active properties of the substrate and the intermediates involved. It should be noted that there is negligible conversion with propanol as the reactant, under the same condition as that for Au/HAP-1.62 applied to acetol conversion above. The introduction of carbonyl group appears to enable the neighbouring hydroxyl of acetol molecule more active over the selective oxidation to aldehyde. It is generally believed that the rate-determing step for the selective oxidation of alcohol is the deprotonation of hydroxyl group with the Au-based catalyst, which can be significantly facilitated via the base support $[27,28]$. However, the existence of carbonyl group also makes acetol more susceptible to aldol-condensation toward formation of heavy side products under strong base support/catalyst such as $\mathrm{MgO}$ [49], as shown by entry 2 of Table 4 in our case. Moreover, the obtained intermediate PA, consisting of two neighbouring carbonyl groups, is even more active and prone to diverse acid or base catalyzed reactions. For instance, beside aldol-condensation possibly 
occurred on both carbonyl groups, it can also undergo Cannizzaro reaction $[8,9]$ under relatively strong alkaline support or 1,2-hydride shift upon Lewis acid [7], leading to the formation of MLA, as also evidenced from entry 7 of Table 4 in our work. All these demonstrate that the base strength in the catalyst support is the very delicate and elegant part to successfully manipulate the selectivity over the varied products. Hence it appears that HAP provides exactly the appropriate strength suitable for the production of MPA, while suppressing the side reactions to a limited extent.

The acid sites also appear indispensable to the high yield of desired MPA product. The acid function can catalyze the carbonyl group of acetol to form its ketal type with methanol, together with simultaneously or subsequently oxidative esterification of the neighbouring hydroxyl group to form MDP. As mentioned earlier, the latter could eventually be converted to MPA, because more water produced would drive the reverse reaction, i.e., making the intermediate ketal (MDP) transform back to the carbonyl (ketone) form through the removal of two attached methoxy groups. Nevertheless, this may be somewhat functioned to protect the active carbonyl group, as typically adopted in organic synthesis, against from the side reactions like aldol-condensation that could readily occur in our case. Moreover, it may even play a more critical role over the reaction of the formed intermediate PA, which is widely accessible a variety of reactions like condensation, Carnnizzaro reaction competing with the selective oxidation. Therefore, the reaction rate toward the desired route is the key to achieve a desired high yield of MPA. The existence of relatively strong acid sites in HAP could enhance the formation of hemiacetol, which is then rapidly oxidized to MPA under Au nanoparticles promoted by the support's base function. During the reaction course, the extremely active intermediate, namely PA, is rapidly consumed, which in return limits those competing side reactions. It should be noted that the change of ratio of Ca to P in varied HAP supports should not significantly alter the inherent strength of the acid or base sites, as evidenced by negligible peak shift in $\mathrm{CO}_{2}$-TPD and $\mathrm{NH}_{3}$-TPD results (Fig. 4); but instead, it does cause the significant change over the ratio of acid-base sites, as summarized in Table 3. The optimized selectivity occurring on $\mathrm{Au} / \mathrm{HAP}-1.62$ may lie in its medium ratio of base/acid density, which somehow can provide the best balance to favor the complex reaction of acetol and PA highly selective toward PA formation. The higher base/acid ratio in HAP-1.65 could expose the substrate and the intermediate more vulnerable to condensation or Carnizzalo reactions as reflected by the poorer mass balance and low yield of MLA in entry 3 of Table 5; whereas the lower base/acid ratio may not provide the enough base sites to faciliate the Au-nanoparticle to enhance the selective oxidation steps (i.e., from acetol to PA, and hemiacetol of PA to MPA), also leaving more rooms for such side reactions to proceed as evidenced in entry 1 of Table 5 .

\section{Conclusions}

Supported $\mathrm{Au}$ catalysts with varied acid-base properties were prepared and systematically studied to understand the role of acid-base sites for oxidative esterification of acetol. $\mathrm{Au} / \mathrm{HAP}$ was found to exhibit superior performance toward the production of MPA, compared to other amphoteric catalysts such as $\mathrm{ZnO}$ and $\gamma-\mathrm{Al}_{2} \mathrm{O}_{3}$, which also show better MPA yield than those supports possessing only acid (like $\mathrm{Au} / \mathrm{SiO}_{2}$, $\mathrm{Au} / \mathrm{TiO}_{2}$ ) or base sites (like $\mathrm{MgO}$ ). Au/HAP-1.62 with a Ca to $\mathrm{P}$ ratio of 1.62 exhibited the best performance among the catalysts studied, achieving $87 \%$ selectivity for MPA at $62 \%$ conversion of acetol. The oxidative esterification proceeds via the formation of PA intermediate and the subsequent hemiacetal mechanism. Appropriate strength and balanced ratio of acid and base sites on HAP-1.62 play an indispensable role to the remarkable selectivity for the desired ester product. Its relative weak base strength can accelerate the oxidation step of acetol over $\mathrm{Au}$ catalysts without significantly accelerating the side reactions like Cannizzaro reaction or aldol-condensation with the active PA intermediate formed. A suitable amount of relative strong acid sites and weak base sites in HAP-1.62 facilitate the hemiacetal formation from PA intermediate in a concerted way while suppressing the base-catalyzed side reactions.

\section{Acknowledgments}

This work was supported by the Major Research Plan of National Natural Science Foundation of China (91545114 and 91545203), the National Natural Science Foundations of China (21576227), and the 985 Program of the Chemistry and Chemical Engineering disciplines of Xiamen University.

\section{References}

[1] S. Czernik, A. V. Bridgwater, Energy Fuels, 2004, 18, 590-598.

[2] D. Mohan, C. U. Pittman Jr., P. H. Steele, Energy Fuels, 2006, 20, 848-889.

[3] T. P. Vispute, H. Y. Zhang, A. Sanna, R. Xiao, G. W. Huber, Science, 2010, 330, 1222-1227.

[4] H. M. Wang, J. Male, Y. Wang, ACS Catal., 2013, 3, 1047-1070.

[5] D. Santhanaraj, M. R. Rover, D. E. Resasco, R. C. Brown, S. Crossley, ChemSusChem, 2014, 7, 3132-3137.

[6] D. E. Resasco, S. P. Crossley, Catal. Today, 2015, 257, 185-199.

[7] Y. Wan, M. Q. Zhuang, S. P. Chen, W. D. Hu, J. Sun, J. D. Lin, S. L. Wan, Y. Wang, ACS Catal., 2017, 7, 6038-6047.

[8] E. M. Albuquerque, L. E. P. Borges, M. A. Fraga, J. Mol. Catal. A, 2015, 400, 64-70.

[9] E. M. Albuquerque, L. E. P. Borges, M. A. Fraga, Green Chem., 2015, $17,3889-3899$.

[10] T. Yasukawa, W. Ninomiya, K. Ooyachi, N. Aoki, K. Mae, Ind. Eng. Chem. Res., 2011, 50, 3858-3863.

[11] A. Corma, S. Iborra, A. Velty, Chem. Rev., 2007, 107, 2411-2502.

[12] O. Casanova, S. Iborra, A. Corma, J. Catal., 2009, 265, 109-116.

[13] E. Taarning, A. T. Madsen, J. M. Marchetti, K. Egeblad, C. H. Christensen, Green Chem., 2008, 10, 408-414.

[14] F. Menegazzo, T. Fantinel, M. Signoretto, F. Pinna, M. Manzoli, J. Catal., 2014, 319, 61-70.

[15] G. L. Brett, P. J. Miedziak, N. Dimitratos, J. A. Lopez-Sanchez, N. F. Dummer, R. Tiruvalam, C. J. Kiely, D. W. Knight, S. H. Taylor, D. J. Morgan, A. F. Carley, G. J. Hutchings, Catal. Sci. Technol., 2012, 2, 97-104.

[16] Y. L. Cao, X. Liu, S. Iqbal, P. J. Miedziak, J. K. Edwards, R. D. Arm- 


\section{Graphical Abstract}

Chin. J. Catal., 2019, 40: 1810-1819 doi: S1872-2067(19)63368-1

Oxidative esterification of acetol with methanol to methyl pyruvate over hydroxyapatite supported gold catalyst: Essential roles of acid-base properties

Yan Wan, Congcong Zheng, Xianchi Lei, Mengqi Zhuang, Jinhan Lin, Wenda Hu, Jingdong Lin, Shaolong Wan*, Yong Wang

Xiamen University, China; Washington State University, USA

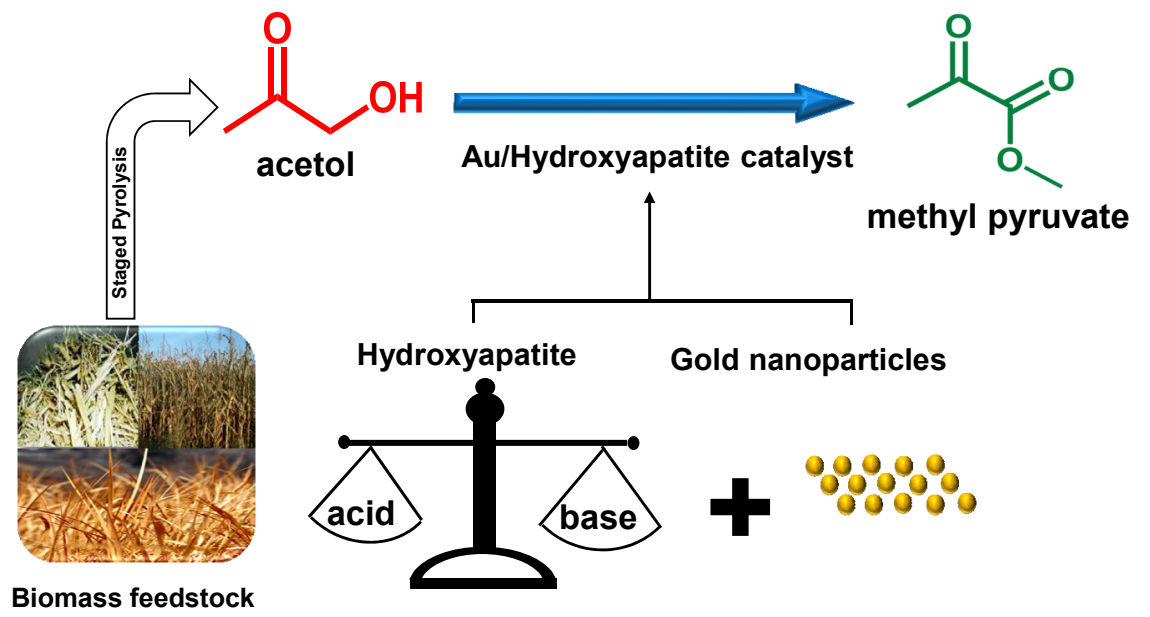

$\mathrm{Au} /$ hydroxyapatite (ratio of $\mathrm{Ca} / \mathrm{P}=1.62$ ) catalyst exhibits superior performance toward the production of methyl pyruvate from biomass-derived acetol, where the featured acid-base properties in hydroxyapatite play an indispensable role.

strong, D. J. Morgan, J. W. Wang, G. J. Hutchings, Catal. Sci. Technol., 2016, 6, 107-117.

[17] Y. Önal, S. Schimpf, P. Claus, J. Catal., 2004, 223, 122-133.

[18] Y. J. Hao, Y. Z. Chong, S. R. Li, H. Q. Yang, J. Phys. Chem. C, 2012, 116, 6512-6519.

[19] B. N. Zope, S. E. Davis, R. J. Davis, Top. Catal., 2012, 55, 24-32.

[20] S. Gil, P. J. Lucas, A. Nieto-Marquez, L. Sanchez-Silva, A. Giroir-Fendler, A. Romero, J. L. Valverde, Ind. Eng. Chem. Res., 2014, 53, 16696-16706.

[21] O. Casanova, S. Iborra, A. Corma, ChemSusChem, 2009, 2, 1138-1144.

[22] S. Liu, K. Sun, B. Q. Xu, ACS Catal., 2014, 4, 2226-2230.

[23] P. Y. Qi, S. S. Chen, J. Chen, J. W. Zheng, X. L. Zheng, Y. Z. Yuan, ACS Catal., 2015, 5, 2659-2670.

[24] M. Manzoli, F. Menegazzo, M. Signoretto, G. Cruciani, F. Pinna, J. Catal., 2015, 330, 465-473.

[25] V. V. Costa, M. Estrada, Y. Demidova, I. Prosvirin, V. Kriventsov, R. F. Cotta, S. Fuentes, A. Simakov, E. V. Gusevskaya, J. Catal., 2012, 292, 148-156.

[26] W. H. Fang, J. S. Chen, Q. H. Zhang, W. P. Deng, Y. Wang, Chem. Eur. J., 2011, 17, 1247-1256.

[27] B. N. Zope, D. D. Hibbitts, M. Neurock, R. J. Davis, Science, 2010, 330, 74-78.

[28] M. S. Ide, R. J. Davis, Acc. Chem. Res., 2014, 47, 825-833.

[29] X. Y. Wan, W. P. Deng, Q. H. Zhang, Y. Wang, Catal. Today, 2014, 233, 147-154.

[30] M. Manzoli, F. Menegazzo, M. Signoretto, D. Marchese, Catalysts, 2016, 6, 107-133.

[31] Y. H. Ke, X. X. Qin, C. L. Liu, R. Z. Yang, W. S. Dong, Catal. Sci. Technol., 2014, 4, 3141-3150.
[32] F. Z. Su, J. Ni, H. Sun, Y. Cao, H. Y. He, K. N. Fan, Chem. Eur. J., 2008, 14, 7131-7135.

[33] F. Z. Su, Y. M. Liu, L. C. Wang, Y. Cao, H. Y. He, K. N. Fan, Angew. Chem. Int. Ed., 2008, 47, 334-337.

[34] X. F. Lang, B. Wen, C. Y. Zhou, Z. F. Ren, L. M. Liu, J. Phys. Chem. C, 2014, 118, 19859-19868.

[35] Z. Y. Liu, R. F. Zhang, S. B. Wang, N. Li, R. Sima, G. J. Liu, P. Wu, G. F. Zeng, S. G. Li, Y. H. Sun, J. Phys. Chem. C, 2016, 120, 6591-6600.

[36] N. Li, S. B. Wang, Q. H. Ren, S. G. Li, Y. H. Sun, J. Phys. Chem. C, 2016, 120, 29290-29301.

[37] A. Abad, P. Concepción, A. Corma, H. García, Angew. Chem., 2005, $117,4134-4137$.

[38] J. Jae, E. Mahmoud, R. F. Lobo, D. G. Vlachos, ChemCatChem, 2014, 6, 508-513.

[39] D. Y. Miao, A. Goldbach, H. Y. Xu, ACS Catal., 2016, 6, 775-783.

[40] J. Huang, L. C. Wang, Y. M. Liu, Y. Cao, H. Y. He, K. N. Fan, Appl. Catal. $B$, 2011, 101, 560-569.

[41] C. L. Xu, Y. Q. Du, C. Li, J. Yang, G. Yang, Appl. Catal. B, 2015, 164, 334-343.

[42] V. C. Ghantani, S. T. Lomate, M. K. Dongare, S. B. Umbarkar, Green Chem., 2013, 15, 1211-1217.

[43] B. Yan, L. Z. Tao, Y. Liang, B. Q. Xu, ACS Catal., 2014, 4, 1931-1943.

[44] M. I. Domínguez, F. Romero-Sarria, M. A. Centeno, J. A. Odriozola, Appl. Catal. B, 2009, 87, 245-251.

[45] Y. J. Zhang, J. H. Wang, J. Yin, K. F. Zhao, C. Z. Jin, Y. Y. Huang, Z. Jiang, T. Zhang, J. Phys. Chem. C, 2010, 114, 16443-16450.

[46] W. Chen, Z. L. Huang, Y. Liu, Q. J. He, Catal. Commun., 2008, 9, 516-521.

[47] M. Milenko, B. O. Fowler, M. S. Tung, J. Res. Nat. Inst. Stand. Technol., 2004, 109, 553-568. 
[48] C. Ampelli, K. Barbera, G. Centi, C. Genovese, G. Papanikolaou, S. Perathoner, K. J. Schouten, J. K. van der Waal, Catal. Today, 2016, $278,56-65$.
[49] S. Abello, F. Medina, D. Tichit, J. Perez-Ramirez, J. C. Groen, J. E. Sueiras, P. Salagre, Y. Cesteros, Chem. Eur. J., 2005, 11, 728-739.

\section{羟基磷灰石负载金催化丙酮醇与甲醇氧化酯化合成丙酮酸甲酯: 酸碱性质的基本作用}

Yan Wan ${ }^{\mathrm{a}}$, Congcong Zheng ${ }^{\mathrm{a}}$, Xianchi Lei ${ }^{\mathrm{a}}$, Mengqi Zhuang ${ }^{\mathrm{a}}$, Jinhan Lin ${ }^{\mathrm{a}}$, Wenda Hu ${ }^{\mathrm{a}}$, JingdongLin ${ }^{\mathrm{a}, \mathrm{c}}$, Shaolong Wan ${ }^{\text {a,b,c, }}$, Yong Wang ${ }^{\mathrm{d}}$

a厦门大学化学化工学院, 福建厦门361005, 中国

$\mathrm{b}$ 厦门大学能源材料化学协同创新中心, 福建厦门361005, 中国

c 厦门大学醇醚酯化工清洁生产国家工程实验室, 福建厦门361005, 中国

d 华盛顿州立大学化学工程与生物工程沃伊兰学院, 普尔曼, 华盛顿 99164, 美国

摘要: 丙酮醇是一种可由木质纤维素类生物质经分步或快速热裂解获得的主要轻质含氧化合物. 本文报道了金基催化剂上, 丙 酮醇可经氧化酯化反应被选择性转化为重要的精细化学品一一丙酮酸甲酯. 研究结果表明具有适宜强度和比例酸碱位点的两性 载体负载金催化剂能够促进氧化酯化反应进行, 同时不加快羟醛缩合缩合和Cannizzaro反应等副反应进行. 其中, 羟基磷灰石(钲 磷比为1.62)负载金催化剂上, 丙酮醇转化率为 $62 \%$, 丙酮酸甲酯选择性可达 $87 \%$.

关键词: 丙酮醇; 酸碱性质; 金; 差基磷灰石; 丙酮酸甲酯

收稿日期: 2019-03-27. 接受日期: 2019-03-29. 出版日期: 2019-11-05.

*通讯联系人. 电子信箱: swan@xmu.edu.cn

基金来源：国家自然科学基金(91545114, 91545203, 21576227); 厦门大学化学与化工985项目。

本文的电子版全文由Elsevier出版社在ScienceDirect上出版(http://www.sciencedirect.com/science/journal/18722067). 